\title{
Hypothyroidism due to enzyme defects
}

\author{
E. M. McGIRR \\ B.Sc., M.D., F.R.C.P. (Lond., Glasg. and Edin.) \\ Professor of Medicine, Muirhead Chair \\ JoHN A. THOMSON \\ M.B., M.R.C.P.(Lond.), M.R.C.P.(Glasg.) \\ Senior Registrar \\ University Department of Medicine, Royal Infirmary, Glasgow, C.4
}

\section{Summary}

Defects in thyroid hormone production, transport and utilization are classified.

Particular attention is given to inherited intrathyroidal defects in hormone synthesis which impair thyroid function and lead to goitre formation and hypothyroidism. Anomalies in biosynthesis may also result from disease or drugs.

Reference is made to the derangement of iodine metabolism that results from iodine deficiency and from insufficient TSH.

Illustrative clinical problems with regard to transport and utilization are quoted, and it is inferred that they lie in rather neglected areas.

Throughout an attempt has been made to show how the clinical problems that are encountered in practice may, by the techniques of investigation available to us, be related to the theoretical list of defects that are included in the classification.

\section{Introduction}

The thyroid hormones thyroxine $\left(\mathrm{T}_{4}\right)$ and triiodothyronine $\left(T_{3}\right)$ play a dominant role in controlling metabolism and are essential for normal growth and development in childhood. The clinical features and laboratory findings indicative of hypothyroidism appear when the amounts of these hormones available to organs, tissues and cells are insufficient.

The term dyshormonogenesis implies a disturbance of normal hormone production. While it may be due to lack of the driving force of thyrotrophin (TSH), as in pituitary hypothyroidism, or to insufficiency of dietary iodine, as in endemic cretinism, it is especially applied to those patients whose condition is due to a defect in the intrathyroidal mechanisms, in particular to those whose condition is due to an inherited anomaly in thyroid hormone synthesis. Theoretically, hypothyroidism may also result from a defect in the mechanism for transporting $T_{4}$ and $T_{3}$ from the thyroid gland to the peripheral tissues, and from a defect in tissue cells which renders them incapable of responding to normal levels of $T_{4}$ and $T_{3}$ in the blood.

Whatever the cause the clinical features of hypothyroidism are identical. They are, however, modified by the age of the patient. If hypothyroidism develops in utero or the early months after birth mental retardation as well as physical stunting may result unless the condition is quicky recognized and adequate treatment instituted. While the common 'athyroidic' or 'dysgenetic' cretin and adult patient with primary hypothyroidism are non-goitrous, the patient whose condition is due to enzymatic dyshormonogenesis is goitrous. Some patients with dyshormonogenesis remain euthyroid, while others become hypothyroid, presumably depending on the severity of their defect. Most cases are familial and where data are sufficient the evidence favours the opinion that the defects are inherited as simple recessive autosomal characteristics. Certainly such a conclusion is fully justified for the organification (Fraser, Morgans \& Trotter, 1960) and iodotyrosine deiodinase or dehalogenase Hutchison and McGirr, 1956) defects.

The various defects postulated in the synthesis, transport and utilization of the thyroid hormones may be classified as follows.

A. Defects in biosynthesis

(a) Intrathyroidal defects: these may be due to:

1. defective trapping of iodide by the thyroid gland

2. defective organification and utilization of the iodine to form monoidotyrosine (MIT) and diiodotyrosine (DIT)

3. defective coupling of MIT and DIT to form $T_{3}$ and $T_{4}$

4. defective deiodination of MIT and DIT with their consequent loss in the urine due to iodotyrosine deiodinase deficiency

5. defective production of thyroglobulin with the formation of an abnormal iodinated protein 
6. defective proteolysis of thyroglobulin

7. miscellaneous and ill-defined defects

(b) Iodine deficiency

(c) Deficient production of TSH

B. Defects in the transport of $T_{4}$ and $T_{3}$ from the thyroid gland to the peripheral tissues

1. plasma binding proteins increased

2. plasma binding proteins decreased

C. Defects in the tissue cells

1. ? deficiency of cellular binding proteins

2. ? failure of mechanism for transportation of $T_{4}$ and $T_{3}$ across the cell membrane.

3. ? refractory end organ response by the tissues.

In this paper we propose in the main to discuss intrathyroidal defects in thyroid hormone synthesis. We shall, however, briefly refer to the other topics where they appear to us relevant to our theme.

\section{Intrathyroidal defects}

The stages involved in the production of $T_{3}$ and $T_{4}$ are fairly well understood in broad outline, although the minute details of the processes involved are not. It is envisaged that iodine is trapped by the thyroid probably in the form of iodide; that iodide is then oxidized to some 'active' form of iodine which is then bound to tyrosine in thyroglobulin to give MIT and DIT; that MIT and DIT are then joined together to give $T_{3}$ and $T_{4}$ within the thyroglobulin molecule. As hormone is required the thyroglobulin is broken down by proteolytic enzymes to release $T_{3}$ and $T_{4}$ which pass into the peripheral blood. MIT and DIT are also released by a similar mechanism but their iodine is removed by a special enzyme (iodotyrosine deiodinase or dehalogenase) and is conserved for re-use within the thyroid.

Defective iodine trapping is a very rare cause of goitrous hypothyroidism having been described on only two occasions (Stanbury \& Chapman, 1960 ; Wolff, Thomson \& Robbins, 1964). This defect is diagnosed by demonstrating the absence of significant accumulation of radioiodine in the thyroid area. The salivary glands also normally trap iodine. In patients with the trapping defect the salivary glands are also defective in this function. The ratio of the radioactivity of a sample of saliva and of plasma obtained simultaneously after a tracer dose of radioiodine in them is approximately unity whereas in normal subjects it is about $20: 1$. The administration of potassium iodide in pharmacological doses may raise the plasma inorganic iodide of such a patient sufficiently to permit iodide to penetrate the thyroid cell by passive diffusion and so allow sufficient hormone to be produced to make the patient euthyroid.

Failure of organification was the first defect to be described by Stanbury \& Hedge (1950). It is readily detected after the administration of radioiodine. The iodine which has been accumulated but not utilized to form MIT and DIT is easily dischargeable by perchlorate or thiocyanate. There appears to be a defect in the peroxidase enzyme system. Failure of organification may be associated with a high tone nerve deafness (Pendred's syndrome). Patients with Pendred's syndrome frequently remain euthyroid.

Defective coupling of MIT and DIT has been occasionally and tentatively propounded (Stanbury, Ohela \& Pitt-Rivers, 1955; Stanbury, 1966). The precise details of coupling are unknown. It has never been shown to be an enzymatic process, and indeed it may depend upon the molecules of MIT and DIT being in the correct geometric positions on the thyroglobulin molecule. Such an arrangement could well be upset if the thyroglobulin molecule was abnormal, or if the gland was very iodine deficient resulting in the molecules of MIT and DIT being too far apart to permit their coupling (Joseph \& Job, 1958). This latter explanation seems unlikely because the coupling process is normal in other dyshormonogenetic goitres which are just as iodine deficient. Other mechanisms of coupling have been postulated. For example it has been suggested that coupling may occur between one molecule of DIT and one of diiodophenylpyruvic acid (DIIPPA). We ourselves have seen a patient with a presumptive coupling defect with a pattern of iodoamino acids in the thyroid consistent with the presence of the pyruvic acid analogues of the iodotyrosines (Murray et al., 1965a). Recently Surks, Weinbach \& Volpert (1967) have described DIIPPA in the rat thyroid. In practice most cases claimed to have a coupling defect have been examples of goitrous hypothyroidism in which other known defects of thyroid hormone synthesis have been eliminated. The thyroid glands at operation $48-72 \mathrm{hr}$ after radioiodine administration have been shown to contain abundant MIT and DIT but little or no $T_{3}$ or $T_{4}$. Otherwise the diagnosis has been made on the basis of negative criteria. A more positive diagnostic approach awaits eludication of the coupling mechanism.

When the iodotyrosine enzyme system is defective MIT and DIT escape in large amounts from the thyroid gland into the blood and thence into the urine taking their iodine with them. Individuals with this defect constituted the first 
group of patients with dyshormonogenesis seen by the authors. The precise diagnosis is readily made by demonstrating that such subjects excrete in the urine a substantial amount of orally or intravenously administered $\mathrm{M}^{131} \mathrm{IT}$ or $\mathrm{D}^{131} \mathrm{IT}$ as iodotyrosine and do not break down these compounds so that iodide is the main excretion product as occurs in normal individuals. The defect is confirmed by showing that thyroid tissue obtained at operation is unable to deiodinate added iodotyrosines in vitro. Cases have been described in which the thyroid gland was unable to deiodinate iodotyrosines but the peripheral blood was able to do so (Kusakabe \& Miyake, 1964). Presumably in this situation some of the iodine liberated by peripheral deiodination can be conserved provided the thyroid enlarges: or, expressed in another way, the need for more iodine conservation and more frequent recycling through the incompetent thyroid to make good the loss from the thyroid of the iodotyrosines leads to goitre formation. Further work in such partial cases is required before such a speculative explanation can be accepted as established.

Our experience of the iodotyrosine deiodinase or dehalogenase defect has been in the main with two large kindreds (Hutchison \& McGirr, 1956; Murray et al., 1965b), one of tinker stock from the West of Scotland and the other, apparently unrelated, from Dumfries. In both these families genetic studies showed that the defect was transmitted as an autosomal recessive characteristic; some of the apparently unaffected relatives were shown to have minor defects in the deiodination of MIT. The thyroid gland of one of our patients unconnected with the above families showed a histological picture indicative of neoplasia (McGirr et al., 1959). Crooks, Greig \& Branwood (1963) have described a similar case.

Many patients have been described who produce an abnormal iodinated protein. Indeed this is probably the commonest defect, though the reports of individual groups of workers such as ourselves tend to be biased by a misleadingly high proportion of one anomaly which by chance comes their way. Several different types of abnormal iodoprotein have been reported. Instead of normal thyroglobulin these patients produce a protein which runs on paper electrophoresis in the position of serum albumin or even in advance of the albumin band-pre-albumin. In some cases more than one type of abnormal protein is present (Murray et al., 1965a). These patients usually present with familial goitre and are as likely to be euthyroid as hypothyroid.
Radioiodine studies give a 'thyrotoxic' pattern of rapid trapping of ${ }^{131} \mathrm{I}$ and an elevated protein-bound ${ }^{131} \mathrm{I}\left(\mathrm{PB}^{131} \mathrm{I}\right)$ at $48 \mathrm{hr}$. The PB $^{131}$ I consists of an abnormal iodinated protein which cannot be extracted with butanol: the $\mathrm{BE}^{131} \mathrm{I}$ is low. The diagnosis is confirmed by examination of the electrophoretic pattern of the thyroid proteins, and by their ultracentrifugation which reveals the presence of a light-weight iodoprotein. It seems likely that in time more refined techniques will delineate more clearly the various anomalies that are at present included in the broad term, iodoprotein defect.

It is at least theoretically possible that the finding of an abnormal iodinated protein may on occasion reflect not the production of an abnormal protein but rather be due to a defect in the proteolytic enzyme system responsible for breaking down thyroglobulin. Two patients in this category have been described by Pittman \& Pittman (1966) and we consider that we have seen one further case in our own clinic. The techniques for assessing protease activity in the thyroid are, however, unsatisfactory. There are sampling problems too and it has to be remembered that the activity of only a small portion of the thyroid gland is measured. It seems reason 8 able therefore to state that although it is likel that such a defect exists there is as yet no cone clusive proof of its existence.

Despite the use of a whole variety of techniques available at present for the elucidation of defects in thyroid metabolism some cases remain obscure. We (Murray et al., 1966) recently reported a family in which goitre was apparently inherited through five generations in an autosomal dominant fashion. All tests available to us were applied to the in vivo and in vitro study of the thyroids of these patients with negative results. It is debatable whether they should be included with dyshormonogenetic cases. The goitres were unusual in that even at an early age they showed unusual calcification. Their histology did not show the gross and generalized hyperplasia and the pleomorphism usually associated with dyshormonogenetic goitres. Indeed the picture was in many ways similar to that seen in a long-standing non-toxic goitre in an elderly individual.

Dyshormonogenesis though seen in its most typical form in the group of cases we have discussed is not an exclusive feature of inherited intrathyroidal defects in hormone biosynthesis. Blocks of hormone synthesis with goitre formation and with or without the features of hypothyroidism may result from goitrogens, whether naturally occurring or iatrogenic. In certain dis- 
ease processes anomalies in synthesis are commonly found. For example in Hashimoto's autoimmune thyroiditis a minor defect in organification is found in about half the cases and an abnormal iodoprotein in the majority (Murray \& McGirr, 1960). An abnormal iodoprotein may be found in thyroid cancer and occasionally in non-toxic goitre (Pitt-Rivers \& Tata, 1960).

\section{Iodine deficiency}

Iodine deficiency produces characteristic changes in iodine metabolism (Wayne, Kontras \& Alexander, 1964) with a low value for plasma inorganic iodine (PII), and increased thyroid avidity for tracer doses of radioiodine. The pattern of hormonogenesis is altered with an increased amount of MIT relative to DIT and of iodotyrosines relative to iodothyronines.

Endemic goitre is the classical example of the result of severe iodine deficiency, but there are good reasons to believe that other factors are often if not usually also involved. Genetic predisposition seems to be especially important in endemic cretinism, but there is also an individual factor as far as the goitre itself is concerned. In endemic areas non-goitrous individuals can be shown by present-day techniques to be as iodine deficient as those who are goitrous (Malamos et al., 1966). Furthermore up to the age of puberty goitre is equally common in males and females but after puberty goitre is more common in females.

Anomalies in iodine metabolism may sometimes occur in endemic goitres but whether they are a consequence or a cause of the cellular hyperplasia is unknown. The goitre may allow as much inorganic iodine to leak from it as it uses in hormone production (Ermans, Dumont \& Bastenie, 1963). Iodotyrosines are sometimes detected in the circulation, and so are butanolinsoluble iodoproteins (Soto et al., 1967). Recently in the sera of a group of patients studied in an endemic goitre region in the Argentine, Soto et al. (1967) found a very high incidence of positive tests for antithyroglobulin antibodies. They explained the development of goitre in some individuals and not in others on the basis of a preestablished genetically determined, diminished immunological tolerance. Whether such findings in endemic areas are the exception or the rule is obviously as yet unknown.

In many but not all hospital patients seen in this country with sporadic goitre iodine metabolism assumes an iodine deficiency pattern (Wayne et al., 1964), which suggests that iodine deficiency may be a significant cause of sporadic goitre. By contrast, otherwise healthy individuals in a community whose thyroids have enlarged sufficiently to be visible and palpable but who do not have large goitres do not appear to be iodine deficient (Greig et al., 1967). This finding and other bits of evidence including the observation that sporadic goitres are more common in females and that hormone synthesis may be deranged in them (Pitt-Rivers, Hubble \& Hoather, 1957) as well as in cases of familial goitre (McGirr, 1960) indicate that factors other than iodine deficiency are involved in the development of sporadic goitre.

\section{Deficient production of TSH}

If the supply of TSH is inadequate the whole mechanism of trapping iodine and synthesizing the thyroid hormones becomes defective. The thyroid becomes less avid for iodine and it has difficulty in producing iodotyrosines, particularly diiodotyrosine, and iodothyronines. The mode of action of TSH on the thyroid is poorly understood. Deficiency of TSH in the adult is likely to be accompanied by evidence of deficiency of other anterior pituitary factors, particularly ACTH and the gonadotrophins. Occasionally in childhood there is an isolated deficiency of TSH leading to secondary hypothyroidism.

\section{Defects in the transport of $T_{3}$ and $T_{4}$}

The thyroid hormones travel in the peripheral blood bound to plasma proteins. The one with the highest specificity for $T_{4}$ is an interalpha globulin called thyroxine binding globulin (TBG) The other binding proteins are albumin, which has a large binding capacity but low specificity and thyroid binding pre-albumin (TBPA) a binding protein running in front of albumin on paper electrophoresis. This latter protein is subject to alteration in acute non-thyroidal illness (Oppenheimer et al., 1963). $T_{3}$ is rather less firmly bound to TBG than $T_{4}$ and is not bound at all to TBPA. This is thought to account, at least in part, for the more rapid clinical effect of $T_{3}$ as compared to $T_{4}$.

Patients have been described with lowered TBG levels in association with thyrotoxicosis (Lemarchand-Beraud, Assayah \& Vanotti, 1964 ; Cavalieri, 1961) or without thyroid abnormality (Tanaka \& Starr, 1959); with increased TBG levels in association with hypothyroidism (Lemarchand-Beraud et al., 1964) or without clinical thyroid abnormality (Florsheim et al., 1962). The TBG level is also elevated in pregnancy and following the administration of oestrogens (including oral contraceptives) and is lowered by drugs of the hydantoin series and by androgens.

Alterations in the TBG levels do not seem to be causally related to clinically abnormal thy- 
roid states but are usually diagnosed by the finding of a PBI level in the serum which is out of keeping with the clinical status of the patient, thus leading to more exact estimations of the TBG capacity being performed. It must be presumed that an equilibrium is reached in these patients between the binding proteins of the plasma, the circulating free thyroxine and the cellular binding proteins which allows a normal level of free thyroxine to be offered to the cells.

Both diminished levels of TBG and elevated levels of TBG have been reported in several members of a family. The pedigrees of the affected families are consistent with each of these traits being transmitted by X-chromosome linked dominant inheritance (Nikolai \& Seal, 1967; Jones \& Seal, 1967).

\section{Peripheral defects}

Theoretically there could be at least three types of peripheral defect:

(1) defective binding proteins in the peripheral tissues to accept thyroxine from the plasma

(2) failure of the mechanism for transporting the hormones across the cell membrane to the site of action

(3) failure of the peripheral tissues to respond

There are no techniques at present available by which such mechanisms may be studied and defects detected and elucidated. Our shortcomings are unfortunate as there certainly seem to be patients, as some of the following examples show, who have some peripheral defect which cannot at present be clearly delineated. A peripheral defect was suggested by us (Hutchison, Arneil \& McGirr, 1957) to be present in a cretin who failed to respond to dry thyroid, which we had good reason to believe was potent, but responded to triiodothyronine. Unfortunately the response to thyroxine was not tested.

Recently we described patients with dyshormonogenetic goitres of the iodotyrosine deiodinase (dehalogenase) type, who showed abnormal handling of intravenously administered ${ }^{131} \mathrm{I}-\mathrm{T}_{4}$ without there being any significant change in TBG levels (Thomson \& Wallace, 1966).

An apparent lack of response to the circulating thyroid hormones has been noted as a familial disorder in several members of a family who had high $\mathrm{PB}^{127} \mathrm{I}$ and $\mathrm{BE}^{127} \mathrm{I}$ levels, who were euthyroid, and who had normal TBG levels (Refetoff, De Wind \& De Groot, 1967). These findings were associated with stippled epiphyses, which could not be related to a previous episode of hypothyroidism, and with deaf-mutism.
A contrasting abnormality has been suggested by Luft et al. (1962) who described a patient with hypermetabolism but with a normal PB $^{127} \mathbf{I}$. They postulated that there was a defect at the mitochondrial level which resulted in a loss of capacity for respiratory control at a subcellular level.

Though the case material appears fragmentary and the investigations, by virtue of a lack of appropriate techniques, are limited we consider that some reference to clinical problems in relation to hormone transport and peripheral utilization is desirable if for no other reason than to direct attention to them and the need for their more intensive study.

\section{Conclusions}

The assertion that dyshormonogenesis plays a fundamental aetiological role in the evolution of thyroid dysfunction is certainly true for inherited intrathyroidal defects of hormone synthesis. Presumably in these cases difficulty in hormone production leads to overactivity of the anterior pituitary, increased production of TSH with consequent thyroid hyperplasia and enlargement which in greater or lesser degree compensates for its fundamental inefficiency. We find as a result the clinical conditions of familial goitre or sporadie (non-endemic) goitrous cretinism and hypothyrois dism.

Where the dyshormonogenesis is a result of or is associated with other conditions such as Hashimoto's autoimmune thyroiditis or iodine deficiency the aetiological contribution of the dyshormonogenesis to the clinical and metabolic status of the affected individual is uncertain. It is, however, important to an understanding of the pathogenesis of such conditions that we should be aware that there may be an accompanying derangement in thyroid function and that in appropriate circumstances we should be prepared to study it with a view to assessing its significance and relationship to the primary condition.

Theoretical considerations suggest that more thought and investigational effort should be devoted to the study of hormone transport and peripheral utilization. Past investigations, particularly in the latter field, have been hampered by inadequate techniques. Undoubtedly defects of transport occur and there is evidence that some of them are hereditary. So far, however, they have not been shown to be responsible for goitre production or hypothyroidism. Most if not all of the reports which suggest defects in utilization have so far been more speculative than factual. 


\section{References}

Cavalieri, R.R. (1961) Hyperthyroidism and decreased thyroxine binding by serum proteins. J. clin. Endocr. 21, 1455.

Crooks, J., Greig, W.R. \& Branwood, A.W. (1963) Dyshormonogenesis and carcinoma of the thyroid gland. Scot. med. J. 8, 303.

ERmans, A.M., Dumont, J.E. \& Bastenie, P.A. (1963) Thyroid function in a goitrous endemic: II. Non-hormonal iodine escape from the goitrous gland. J. clin. Endocr. 23, 550.

Florsheim, W.H., Dowling, J.T., Meister, L. \& Bodfish, R.E. (1962) Familial elevation of serum thyroxine binding capacity. J. clin. Endocr. 22, 735.

Fraser, G.R., Morgans, M.E. \& Trotter, W.R. (1960) The syndrome of sporadic goitre and congenital deafness. Quart. J. Med. 29, 279.

Greig, W.R., Boyle, J.A., Duncan, A., Nicol, J., Gray, M.J.B., BuchanaN, W.W. \& MCGIRR, E.M. (1967) Genetic and non-genetic factors in simple goitre. Evidence from a twin study. Quart. J. Med. 142, 175.

Hutchison, J.H. \& McGiRR, E.M. (1956) Sporadic nonendemic goitrous cretinism. Hereditary transmission. Lancet, i, 1035.

Hutchison, J.H., ARneil, G.C. \& McGirR, E.M. (1957) Deficiency of an extra-thyroid enzyme in sporadic cretinism. Lancet, ii, 314.

Jones, J.E. \& SEAL, U.S. (1967) X-chromosome linked inheritance of elevated thyroxine-binding globulin. J. clin. Endocr. 27, 1521.

JosePH, R. \& JoB, J.C. (1958) Congenital hypothyroidism with anomaly of iodotyrosine condensation: familial incidence: physiopathological discussion. Arch. franc. Pediat. 15, 464.

Kusakabe, T. \& MiYaKe, T. (1964) Thyroidal deiodination defect in three sisters with simple goitre. J. clin. Endocr. 24, 456.

Lemarchand-Beraud, Th., Assayah, M.-R. \& Vanotti, A. (1964) Alteration of thyroxine-binding protein in clinically hypo- and hyper-thyroid patients with normal PBI level. Acta endocr. (Kbh.), 45, 99.

Luft, R., Ikkos, D., Palmieri, G., Ernster, L. \& Afzelius, B. (1962) A case of severe hypermetabolism of nonthyroid origin with a defect in the maintenance of mitochondrial respiratory control: A correlated clinical, biochemical and morphological study. J. clin. Invest. 41, 1776.

McGirR, E.M. (1960) Clinical Endocrinology (Ed. by E. B. Astwood), vol. 1, p. 133. Grune \& Stratton, New York.

MCGirR, E.M., Clement, W.E., Currie, A.R. \& Kennedy, J.S. (1959) Impaired dehalogenase activity as a cause of goitre with malignant change. Scot. med. J. 4, 232.

Malamos, B., Miras, K., Koutras, D.A., Kostamis, P., Binopoulos, D., Mantzos, J., Levis, G., Rigopoulos, G., Zerefos, N. \& TAssopoulos, C.N. (1966) Endemic goiter in Greece: metabolic studies. J. clin. Endocr. 26, 696.

MURRAY, I.P.C. \& MCGIRR, E.M. (1960) Radioactive iodine studies in the diagnosis of Hashimoto's thyroiditis. Brit. med. J. i, 838.

Murray, I.P.C., McGirR, E.M., Thomson, J.A. \& Hutchison, J.H. (1965a) Current Topics in Thyroid Research (Ed. by C. Cassano and M. Andreoli), p. 813. Academic Press, New York.
Murray, I.P.C., Thomson, J.A., McGirr, E.M., Wallace, T.J., Macdonald, E.M. \& Maccabe, H.J. (1956b) Absent and defective iodotyrosine deiodination in a family, some of whose members are goitrous cretins. Lancet, i, 183.

Murray, I.P.C., Thomson, J.A., MCGirR, E.M., MaCDONALD, E.M., KENNEDY, J.S. \& McLenNAN, I. (1966) Unusual familial goitre associated with intrathyroidal calcification. J. clin. Endocr. 26, 1039.

NikolaI, T.F. \& Seal, U.S. (1967) X-chromosome linked inheritance of thyroxine binding globulin deficiency. J. clin. Endocr. 27, 1515.

Oppenheimer, J.H., Squef, R., Surks, M. \& Hauer, H. (1963) Binding of thyroxine by serum proteins evaluated by equilibrium dialysis and electrophoretic techniques. Alterations in non thyroidal illness. J. clin. Invest. 42, 1769.

Pittman, C.S. \& PitTman, J.A. (1966) A study of the thyroglobulin, thyroidal protease and iodoproteins in two congenital goitrous cretins. Amer. J. Med. 40, 49.

Pitt-Rivers, R., Hubble, D. \& Hoather, W.H. (1957) A chromatographic study of thyroidal iodine metabolism in non-toxic nodular goitre. J. clin. Endocr. 17, 1313.

PitT-Rivers, R. \& TATA, J.R. (1960) The Chemistry of Thyroid Disease. Thomas, Springfield, Illinois.

Refetoff, S., DeWind, L.T. \& De Groot, L.J. (1967) Familial syndrome combining deaf mutusm, stippled epiphyses, goiter and abnormally high PBI: possible target organ refractoriness to thyroid hormone. J. clin. Endocr. 27, 279.

Soto, R.J., Imas, B., Brunengo, A.M. \& GoldberG, D. (1967) Endemic goiter in Misiones, Argentina; pathophysiology related to immunological phenomena. J. clin. Endocr. 27, 1581.

Stanbury, J.B. (1966) The Metabolic Basis of Inherited Disease (Ed. by J. B. Stanbury, J. B. Wyngaarden, and D. S. Fredrickson), p. 215. McGraw-Hill, New York.

Stanbury, J.B. \& Chapman, E.M. (1960) Congenital hypothyroidism with goitre. Absence of an iodide-concentrating mechanism. Lancet, i, 1162.

Stanbury, J.B. \& Hedge, A.H. (1950) A study of a family of goitrous cretins. J. clin. Endocr. 10, 1471.

Stanbury, J.B., Ohela, K. \& Pitt-Rivers, R. (1955) The metabolism of iodine in 2 goitrous cretins compared with that in 2 patients receiving methimazole. J. clin. Endocr. $15,54$.

Surks, M.I., Weinbach, S. \& Volpert, E.M. (1967) Paper presented at the Annual meeting of the American Thyroid Association, Ann Arbor, September 1967.

TANaka, S., STARR, P. (1959) Clinical observations on serum globulin thyroxine-binding capacity, using a simplified technique. J. clin. Endocr. 19, 84.

Thomson, J.A. \& Wallace, T.J. (1966) Anomalous values for the half-life of radiothyroxine in dyshormonogenetic goiter. J. clin. Endocr. 26, 875.

Wayne, E.J., Koutras, D.A. \& Alexander, W.D. (1964) Clinical Aspects of Iodine Metabolism. Blackwell Scientific Publications, Oxford.

WolfF, J., Thomson, R.H. \& Robins, J. (1964) Congenital goitrous cretinism due to the absence of iodide-concentrating ability. J. clin. Endocr. 24, 699. 